\title{
Correlates of Canadian Prairie summer rainfall: implications for crop yields
}

\author{
Ray Garnett ${ }^{1, *}$, Niru Nirupama ${ }^{2}$, C. Emdad Haque ${ }^{3}$, T. S. Murty ${ }^{4}$ \\ ${ }^{1}$ Agro Climatic Consulting, 1340 Aikins Street, Winnipeg, Manitoba R2V 2C7, Canada \\ ${ }^{2}$ School of Administrative Studies, Rm. 210A, Atkinson College, York University, 4700 Keele Street, Toronto, \\ Ontario M3J 1P3, Canada \\ ${ }^{3}$ Natural Resource Institute, University of Manitoba, 70 Dysart Road, Winnipeg, Manitoba R3T 2N2, Canada \\ ${ }^{4}$ Department of Civil Engineering, University of Ottawa, 161 Louis Pasteur Room A106, Ottawa, Ontario K1N 6N5, Canada
}

\begin{abstract}
Large-scale atmospheric circulations and anomalies have significant influence upon seasonal weather over many parts of the world. We examined the impact of sunspot activity and large-scale atmospheric features on regional seasonal weather, as well as implications for crop yield and agronomy. The atmospheric variables analyzed included the stratospheric quasi-biennial wind oscillation (QBO), El Niño/Southern Oscillation (ENSO), and North American snow cover (NAS) on Canadian summer rainfall, regarded as a key variable for establishing grain yield. Because the study is an exploratory one, we focused on correlation coefficients between selected variables. The analysis is based on $55 \mathrm{yr}$ of atmospheric, crop yield and climatic data for $>50$ weather stations over the Canadian Prairie region. Our study reveals that high (low) sunspot activity, an easterly (westerly) phase of the QBO, persistent La Niña (El Niño) conditions and heavier (lighter) than normal NAS in seasons leading up to the summer months are associated with low (high) summer rainfall.
\end{abstract}

KEY WORDS: Summer rainfall $\cdot$ Snow cover $\cdot$ Sunspots $\cdot$ ENSO $\cdot$ QBO $\cdot$ Canadian Prairie $\cdot$ North America

Resale or republication not permitted without written consent of the publisher

\section{INTRODUCTION}

Between 1988 and 1998 Canada was the second largest exporter of wheat in the world market. Institutionally, the Canadian Wheat Board, which is headquartered in Winnipeg, administers export of this grain. The prairie region of Western Canada, producing an annual average of 22.9 million tonnes between 1990 and 1995 (Garnett et al. 1998), is the principal grain producing region of Canada. It is, however, important to look into the deviations in total crop production from the average production. Wheaton (1991) draws attention to interannual climatic variability that contributes to large deviations in production and poses a threat to the agroecosystem and rural sustainability.

Statistical analyses of the impact of large-scale atmospheric features, such as the El Niño/Southern Oscillation (ENSO), the stratospheric quasi-biennial wind oscillation (QBO) and Eurasian snow cover, on Indian monsoon droughts and floods and world grain yields have been made elsewhere (Garnett \& Khandekar 1992). In the North American regional context, such an analysis is yet to be conducted. This study attempts to determine the correlates of sunspots, QBO, ENSO and North American snow cover (NAS) with Canadian Prairie summer precipitation, regarded as a key factor in establishing grain yield. Numerous studies have shown the influence of ENSO on Canadian Prairie weather. This study replicates previous ENSO studies with a different climatic dataset and explores further the influence of other factors.

When sea surface temperatures (SSTs) in the central and eastern Pacific are above normal during winter and early spring (that is, a prevailing El Niño), precipitation during the summer months is higher than normal in the Canadian Prairie (Garnett \& Khandekar 
1992, Shabbar et. al. 1997, Garnett et. al. 1997, 1998, Hsieh et al. 1999, Garnett 2002). This condition favors spring wheat yield. Conversely, when SSTs in the central and eastern equatorial region of the Pacific Ocean are below normal during winter and early spring (that is, a prevailing La Niña), precipitation over the Canadian Prairies during the months of June and July is below normal. Consequently, wheat yields are reduced. Garnett (2002) found that statistical relationships with ENSO were strongest in Saskatchewan's brown soil zone in the southwest part of the province and weakest in the black soil zone in the northeast part of the province. In short El Niño is a friend and La Niña a foe to spring wheat growing in the Canadian Prairies.

Among many other large-scale atmospheric features, the sunspot cycle, as a determinant of regional seasonal weather conditions, has received attention from a number of researchers. The Max Planck Society (press release, October 28, 2004; available at http:// www.mpg.de/english/portal/index.html) puts forth the mechanism by which sunspot activity may affect precipitation. Sunspot activity and cosmic ray intensity are inversely correlated, and therefore during periods of high (low) sunspot activity cosmic ray intensity diminishes (increases). Ions produced by cosmic rays act as condensation nuclei for a larger suspension of particles and thus contribute to cloud formation. With increased solar activity (and stronger magnetic field) the cosmic rays decrease and with it the amount of cloud coverage, resulting in a rise of temperatures on the earth. Conversely, a reduction in solar activity produces lower temperatures.

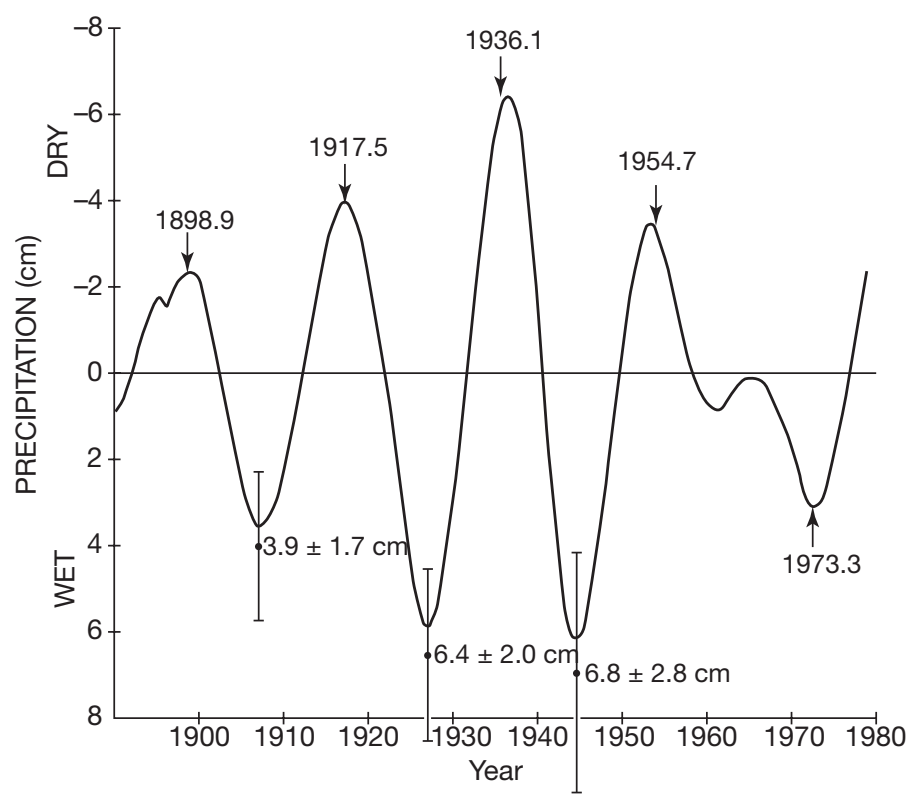

Fig. 1. Lunisolar $19 \mathrm{yr}$ mean wave train for 18 records from Illinois (after Currie \& O'Brien 1990)
Thompson (1973) pointed to the effects of the double sunspot cycle on the USA Corn Belt and middle latitudes. Currie (1984) studied drought and floods induced with 18.6 and $11 \mathrm{yr}$ periodicities in western North America. As shown in Fig. 1, Currie \& O'Brien (1990) found a luni-solar-induced $19 \mathrm{yr}$ mean wave train for precipitation for 18 weather stations in Illinois, implying that solar activity influenced dryness around the years of 1899, 1918, 1936, 1956 and 1980. Udelhofen \& Cess (2001) hypothesize that cloud variability may be affected by a modulation of atmospheric circulation resulting from variations of atmospheric heating caused by the action of solar UV on ozone, as cloud cover is positively correlated with solar variability in most regions of the USA. An exception was the cloud cover in the Great Lakes region, which was negatively correlated with sunspot numbers. Spectral analysis revealed a statistically significant cloud cover signal at a period of 11 years.

Annual precipitation over the Canadian Prairies is above normal near sunspot minima and below normal near sunspot maxima (Currie \& Venkatarangan 1978). The June-July period in Saskatchewan between 1950 and 2004 has generally been warmer and drier than normal, corresponding with peaks in the 22 and $11 \mathrm{yr}$ sunspot cycle (Garnett 2005). The double sunspot cycle peaked in 1918, 1938, 1958, 1979 and 2001. The present study tests the hypothesis that high sunspot activity is conducive to low rainfall and vice versa.

The QBO has been recognized as an important factor in foreshadowing Indian monsoon rainfall. Mukherjee et al. $(1979,1985)$ identified that a strong easterly phase of the QBO is associated with weak monsoons, and a weak easterly/westerly phase with active monsoons, and concluded that $15 \%$ of the variability in monsoon rainfall is associated with the pattern of the QBO. Van Loon \& Labitzke (1988) described how solar flux influences various atmospheric parameters, depending on the phase of the QBO, revealing its modulating influence on global climate. Gray et al. (1992) described how the easterly phase of the QBO can help initiate El Niño events, depending on the state of the 'warm pool' and annual cycle. The easterly phase of the QBO appears to play a role in initiating every second El Niño event.

With respect to the Canadian Prairies we hypothesize that the phase of the QBO influences the orientation of thunderstorm anvils as they move from west to east. A westerly phase of the QBO causes an eastward and more upright extension of thunderstorm anvils, which is conducive to higher convection and outflow. Increased convection is more conducive to rainfall. Conversely with an easterly phase of the QBO thunderstorm anvils have a more westward orientation which is less conducive to convection. 
Drought monsoons in India are preceded by anomalously heavy Eurasian snow cover; they are associated with much more snow in all seasons than are flood monsoons (Garnett \& Khandekar 1992). Heavy Eurasian snow cover during the winter months inhibits Indian summer monsoon activity. Shabbar \& Khandekar (1996) and Shabbar et al. (1997) observed that El Niño usually brings warmer and drier winters to western Canada, while La Niña usually brings colder and wetter winters to this region. The present study tests the hypothesis that increased (decreased) spatial extent of NAS inhibits (favors) Canadian summer rainfall much like Eurasian snow cover inhibits Indian monsoon rainfall. This implies that El Niñoinduced mild, dry winters in North America are seldom followed by dry summers on the Canadian Prairies.

A conceptual model, developed after Khandekar (1996) and depicted in Fig. 2, shows the combinations of sunspot activity, phase of the QBO, ENSO state and NAS extent required to produce a wet or dry summer over the Canadian Prairies. By assessing the respective influence of each of the 4 forcing functions in the spring months one can gauge the likelihood of a wet, dry or intermediately wet summer. Fig. 2 shows the ideal scenarios for a wet or dry summer. There will be years in which 2 forcing functions point to a wet summer and 2 towards a dry summer and so on. The strength and frequency of significant correlations suggests the relative strength of the 4 forcing functions. Low sunspot activity leads to high levels of cosmic rays, more ions, more condensation nuclei, more suspension of particles and increased cloudiness. The conceptual model presents the sunspot mechanism proposed by the Max Planck Society and supported by the studies of Currie (1978) and Garnett (2005) over the Canadian Prairies, Currie (1990) for Illinois and Udelhofen \& Cess (2001) for the Great Lakes Region of the USA. A westerly phase of the QBO causes an eastward and more upright extension of thunderstorm anvils, which is more conducive to outflow, and increased convection. When SSTs in the central equatorial Pacific are warmer than air temperatures (strong El Niño) there is an upward flux of water vapor into the atmosphere, convection, heat released by condensation, strengthening westerlies and a vitalization of the Hadley circulation. Developing El Niño conditions during the winter and spring months results in more zonal flow over the Pacific North American region bringing cooler and wetter weather to the Canadian Prairies. The extension of NAS is below normal because of warmer and drier than normal weather associated with El Niño.

The combinations of sunspot activity, phase of the QBO, ENSO state and NAS extent required to produce a dry summer over the Canadian Prairies can be seen in Fig. 2b. High sunspot activity leads to low levels of cosmic rays, fewer ions, condensation nuclei, and suspended particles, and decreased cloudiness. An easterly phase of the QBO would mean a more westward orientation of thunderstorm anvils, which are less conducive to convection and precipitation. When SSTs are colder than air temperatures (strong La Niña) this produces the opposite influence on atmospheric processes as described above. Developing La Niña conditions during the winter and spring months result in more meridional flow over the Pacific North American region bringing warmer and drier weather to the Canadian Prairies. The extension of NAS is above normal because of colder and wetter than normal weather associated with La Niña.

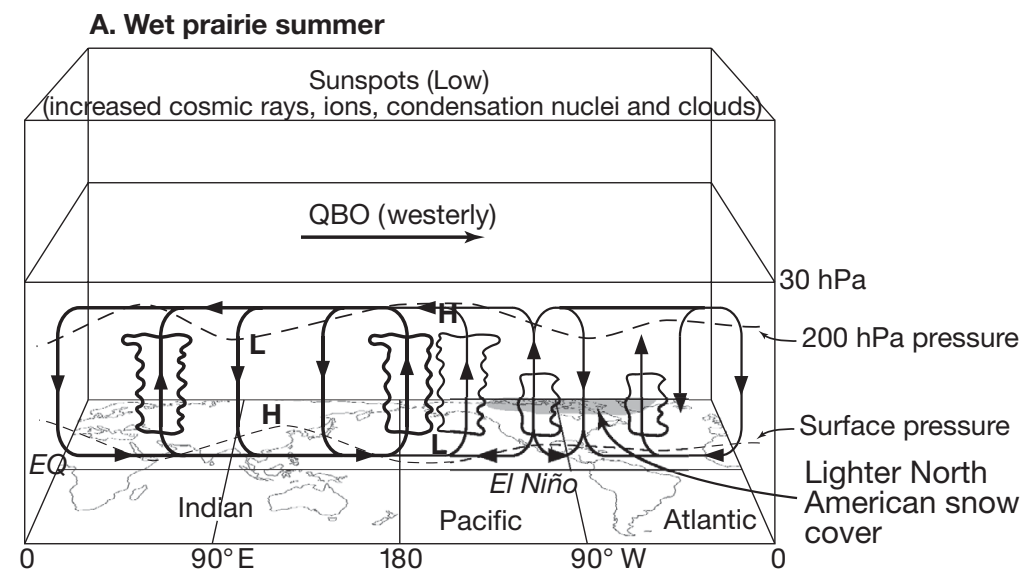

\section{B. Dry prairie summer}

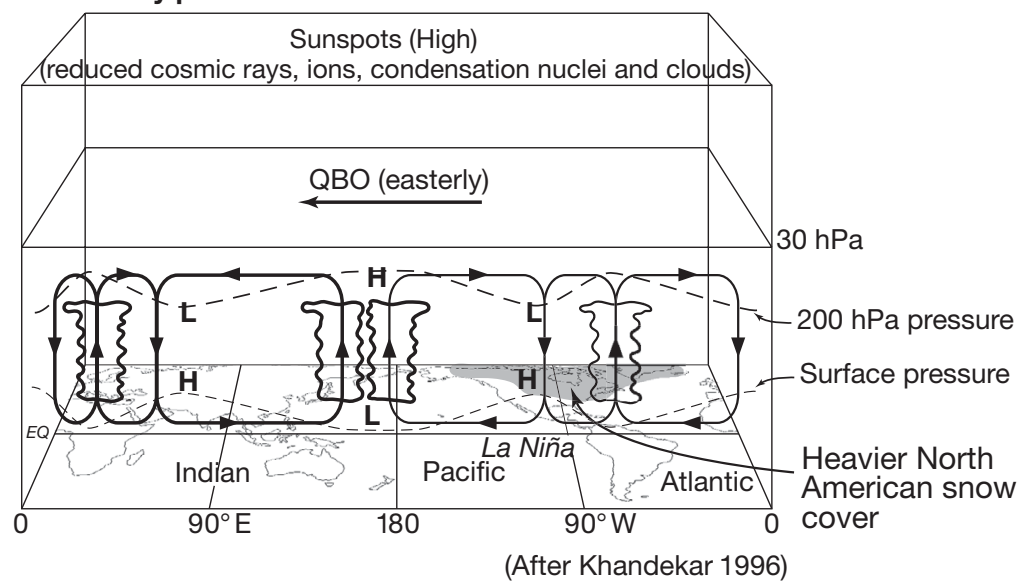

Fig. 2. Conceptual model of factor producing wet and dry prairie summers. H: high, L: low pressure system 
June of 2005 is an excellent case study of a wet summer on the Canadian Prairies. Canadian Prairie precipitation was $197 \%$ of normal, 3 standard deviations above normal and the wettest June for the period 1950-2005. The June 2005 Climate Diagnostics Bulletin reveals a $500 \mathrm{kPa}$ trough at $180^{\circ} \mathrm{W}$ and a corresponding trough on the west coast of North America. The trough at $180^{\circ} \mathrm{W}$ may have evolved with the persistence of warmer than normal SSTs at Niño 4 during the winter and spring months (El Niño conditions). Garnett (2002) compares the trough-ridge-trough alignment that existed in 1951, an El Niño year, with the ridge-trough-ridge alignment of 1988, a well known La Niña and drought year. A trough on the North American west coast is conducive to Colorado Low development and heavy precipitation over the Canadian Prairies as occurred in June of 2005. The sunspot and atmospheric processes were likely similar to that described in the conceptual model for wet summers.

\section{STUDY AREA AND DATA}

The study area is the grain-growing region of the 3 Canadian Prairie Provinces. Fig. 3 shows the geographic location of selected weather stations over the Prairie Provinces, all of which are in or near the graingrowing region. Monthly precipitation and temperature data for 51 weather stations on the Canadian Prairies were obtained from Environment Canada. Only stations that reported more than $80 \%$ of the time for the period 1950-2004 were accepted for use in the study.

The climatic and agricultural data used in this study are for the period 1950-2004, except for NAS, which was only available for the period 1974-2004. Spring wheat and canola yield were obtained from Statistics Canada and the Canadian Wheat Board's Weather and Crop Surveillance crop database. Monthly sunspot data were obtained from the US National Oceanic and Atmospheric Administration (NOAA) Geophysical Data Center in Boulder, Colorado, USA. Historical 30 hpa QBO data, Niño 3 sea surface temperature anomaly (SSTA) data and NAS data were provided by the Climate Prediction Center in Washington, DC. The ENSO indexes used in this study were monthly SSTAs over the Niño 3 region $\left(5^{\circ} \mathrm{N}-5^{\circ} \mathrm{S}, 90-150^{\circ} \mathrm{W}\right)$, Niño 4 region $\left(5^{\circ} \mathrm{N}-\right.$ $5^{\circ} \mathrm{S}, 160^{\circ} \mathrm{E}-150^{\circ} \mathrm{W}$ ) and Southern Oscillation Index (SOI) as originally defined by Walker \& Bliss (1932) and represented by the difference in standardized sea-level pressure between Tahiti $\left(17^{\circ} 33^{\prime} \mathrm{S}\right.$, and $\left.149^{\circ} 37^{\prime} \mathrm{W}\right)$ and Darwin $\left(12^{\circ} 24^{\prime} \mathrm{S}, 130^{\circ} 52^{\prime} \mathrm{E}\right)$.

\section{RESULTS AND DISCUSSION}

Zero order correlation analysis was performed to determine the degree of association between May, June and July temperature and precipitation, and spring wheat and canola yield (Table 1). June and July precipitation is correlated best with spring wheat yield, while May through July precipitation is correlated best with canola yields. Canola and spring wheat are both sensitive to July precipitation and temperature. June precipitation appears less important than May and July precipitation for both spring wheat and canola yields. Growing season temperatures from May through July are significant for both crops.

Because May through July precipitation proved to be a significant factor in determining spring wheat and canola yield correlation, analysis was done with various large-scale atmospheric features including monthly sunspot numbers. Data presented in Table 2 depict that sunspot numbers in 10 out of 12 mo of the year are associated with May through July rainfall. Lower rainfall occurs with high sunspot number, which is consistent with the findings of Currie (1978).

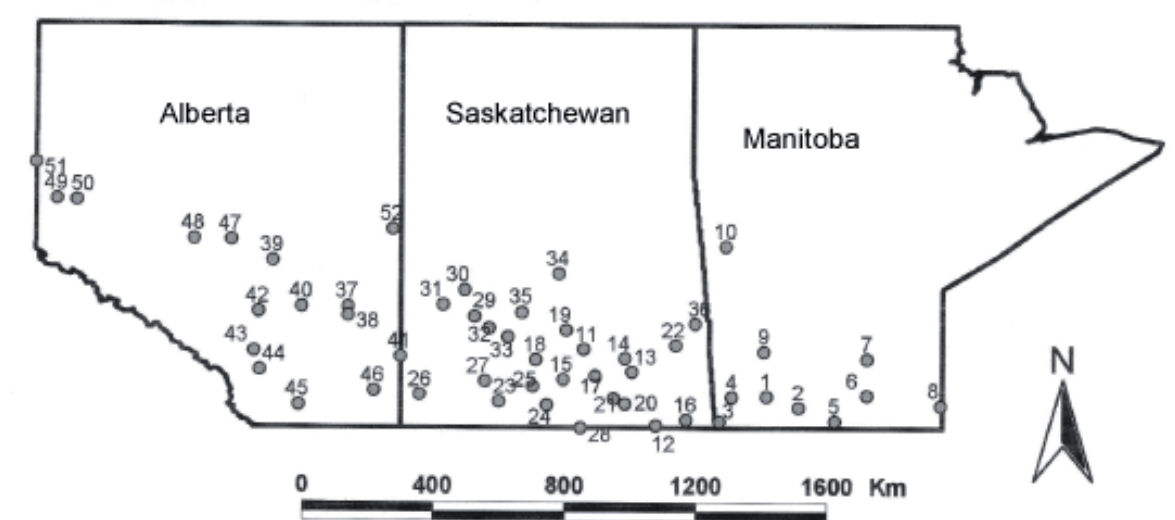

\begin{tabular}{|c|c|c|c|c|}
\hline Manitoba & Saskatchewan & 21. Yellow Grass & 32. Harris & 41. Red Deer \\
\hline 1. Brandon & 11. Duval & 22. Yorkton & 33. Outlook & 42. Calgary \\
\hline 2. Cypress River & 12. Estevan & 23. Aneroid & 34. Prince Albert & 43. High River \\
\hline 3. Pierson & 13. Indian head & 24. Assinaboia & 35. Saskatoon & 44. Lethbridge \\
\hline 4. Virden & 14. Lipton & 25. Coderre & & 45. Medicine Hat \\
\hline 5. Morden & 15. Moose Jaw & 26. Maple Creek & Alberta & 46. Campsie \\
\hline 6. Winnipeg & 16. Oxbow & 27. Swift Current & 36. Brownfield & 47. Whitecourt \\
\hline 7. Arborg & 17. Regina & 28. W. Poplar River & 37. Coronation & 48. Beaverlodge \\
\hline 8. Indian Bay & 18. Tugaske & 29. Biggar & 38. Edmonton & 49. Grande Prairie \\
\hline 9. Dauphin & 19. Watrous & 30. North Battleford & 39. Stettler & 50. Peace River \\
\hline 10. The Pas & 20. Weyburn & 31. Scott & 40. Empress & 51. Cold Lake \\
\hline
\end{tabular}

Fig. 3. Geographic locations of weather stations over the Canadian Prairie Provinces 
Table 1. Correlation coefficients between climatic parameters and grain yield $(\mathrm{n}=55) .{ }^{*} \mathrm{p} \leq 0.05{ }^{* *} \mathrm{p} \leq 0.01$

\begin{tabular}{|lccc|}
\hline Parameter & $\begin{array}{c}\text { Time } \\
\text { period }\end{array}$ & $\begin{array}{c}\text { Correlation coefficient } \\
\text { Spring wheat }\end{array}$ & Canola \\
\hline Temperature & May & 0.13 & 0.18 \\
& Jun & 0.04 & -0.15 \\
Precipitation & Jul & -0.22 & $-0.33^{*}$ \\
& May & $0.31^{* *}$ & $0.25^{*}$ \\
& Jun & $0.27^{*}$ & 0.18 \\
Precipitation anomaly & Jul & $0.51^{* *}$ & $0.28^{*}$ \\
& May-Jun & $0.38^{* *}$ & $0.34^{*}$ \\
& May-Jul & $0.56^{* *}$ & $0.42^{* *}$ \\
Temperature anomaly & Jun-Jul & $0.62^{* *}$ & $0.34^{* *}$ \\
& May-Jun & $-0.34^{* *}$ & $-0.36^{* *}$ \\
& May-Jul & $-0.33^{* *}$ & $-0.23^{*}$ \\
& Jun-Jul & $-0.36^{* *}$ & $-0.38^{* *}$ \\
& & & \\
\hline
\end{tabular}

Phase and strength of the QBO in the autumn and early winter months also appear to influence precipitation during the summer months, an ongoing westerly phase preceding the rainy season being favorable and the easterly phase being unfavorable for rainfall. Unlike other studies, no statistically significant associations were found between ENSO factors and May-July precipitation apart from the SOI in August. This may be because this study uses fewer climate stations with more years of data than previous studies. An inverse correlation was found between April NAS and MayJuly precipitation, suggesting that anomalously high snow cover in April minimizes May-July rainfall.

Because June and July precipitation proved to be a significant factor in determining the spring wheat and canola yield, June-July precipitation was similarly correlated with various large-scale atmospheric features including monthly sunspot numbers. March and April Niño 3.4 SSTAs, May Niño 3 SSTAs and April NAS correlations were significant (Table 2).

The weakness of sunspot number and QBO correlations in Table 2 might be explained by Currie's (1978) finding that solar disturbances were associated with annual rainfall over the Canadian Prairies. Correlating monthly sunspot number with only 2 mo of rainfall as opposed to 3 may explain the weakening in correlations. Similarly a large-scale feature such as the QBO is more likely to correlate with a climatic factor over 3 mo than over 2 .

The range in precipitation was analyzed for sets of 5 years. Fig. 4 shows the sunspot number during the 5 driest, 5 intermediate and 5 wettest May-July periods over the Canadian Prairies. The 5 wettest May-July periods occurred in 1953, 1986, 1991, 1993 and 1999. The 5 driest May-July periods were 1957 , 1958, 1961, 1967 and 1985. Those years ranked near the median were 1950, 1952, 1956, 1987 and 2001.

Sunspot numbers in the driest May-July periods are almost double those of the wettest years. The sunspot numbers for years in which May-July rainfall ranked near the median are between those of the wettest and driest summers in every month except February. The sunspot number in January correlated best with May-July rainfall a full 6 mo in advance of the critical June-July growing period for spring wheat and canola, and $9 \mathrm{mo}$ in advance of harvest for these 2 crops. Performing operational research with this composite has predictive capability, especially when sunspots act in unison with the QBO, ENSO and NAS factors. Their combined influence would produce a

Table 2. Correlation coefficients of various climatic indices vs. precipitation departure from normal over Canadian Prairies $\left(\mathrm{n}=55\right.$, except NAS, where $\mathrm{n}=31$ ). ${ }^{*} \mathrm{p} \leq 0.05 ;{ }^{* *} \mathrm{p} \leq 0.01$

\begin{tabular}{|c|c|c|c|c|c|c|c|c|c|c|c|c|}
\hline & Sep & Oct & Nov & Dec & Jan & Feb & Mar & Apr & May & Jun & Jul & Aug \\
\hline \multicolumn{13}{|c|}{ May-July precipitation anomaly } \\
\hline Sunspots & $-0.25^{*}$ & $-0.24^{*}$ & $-0.23^{*}$ & -0.22 & $-0.31^{*}$ & -0.22 & $-0.26^{*}$ & $-0.25^{*}$ & $-0.27^{*}$ & $-0.23^{*}$ & $-0.26^{*}$ & $-0.25^{*}$ \\
\hline QBO & $0.26^{*}$ & $0.26^{*}$ & $0.25^{*}$ & $0.25^{*}$ & $0.23^{*}$ & 0.19 & 0.18 & 0.13 & 0.03 & -0.08 & -0.10 & -0.11 \\
\hline SOI & -0.06 & -0.02 & 0.00 & 0.03 & 0.06 & -0.13 & -0.04 & -0.13 & 0.01 & -0.02 & -0.17 & $-0.23^{*}$ \\
\hline Niño 3 & -0.01 & 0.00 & 0.01 & -0.07 & 0.00 & -0.04 & 0.09 & 0.04 & 0.15 & 0.06 & 0.08 & 0.04 \\
\hline Niño 3.4 & -0.01 & -0.02 & -0.05 & -0.02 & -0.07 & 0.01 & 0.10 & 0.13 & 0.01 & 0.07 & -0.01 & 0.12 \\
\hline Niño 4 & -0.06 & -0.05 & -0.05 & -0.09 & -0.11 & -0.13 & -0.09 & -0.11 & -0.04 & 0.00 & 0.09 & 0.08 \\
\hline NAS & 0.05 & 0.06 & 0.05 & 0.22 & -0.05 & -0.17 & -0.08 & $-0.32^{*}$ & -0.12 & 0.00 & -0.12 & -0.18 \\
\hline \multicolumn{13}{|c|}{ June-July precipitation anomaly } \\
\hline Sunspots & -0.12 & -0.10 & -0.07 & -0.10 & -0.19 & -0.14 & -0.13 & -0.10 & -0.15 & -0.16 & -0.16 & -0.11 \\
\hline QBO & 0.20 & 0.20 & 0.19 & 0.21 & 0.21 & 0.17 & 0.19 & 0.18 & 0.13 & 0.06 & 0.06 & 0.02 \\
\hline S.O.I. & -0.05 & 0.00 & -0.09 & -0.02 & 0.00 & -0.20 & -0.02 & -0.12 & -0.02 & -0.05 & -0.16 & -0.16 \\
\hline Niño 3 & 0.04 & 0.04 & -0.09 & -0.02 & -0.01 & 0.02 & 0.15 & 0.21 & $0.24^{*}$ & 0.11 & 0.10 & 0.07 \\
\hline Nino 3.4 & 0.03 & 0.04 & 0.04 & 0.06 & 0.07 & 0.12 & $0.23^{*}$ & $0.24^{*}$ & 0.06 & 0.07 & 0.00 & 0.10 \\
\hline Niño 4 & 0.01 & -0.01 & -0.01 & -0.03 & -0.03 & 0.00 & 0.02 & 0.00 & 0.02 & 0.03 & 0.06 & 0.07 \\
\hline NAS & 0.07 & 0.05 & 0.09 & 0.24 & -0.24 & -0.23 & -0.11 & $-0.43^{* *}$ & -0.27 & -0.10 & -0.18 & -0.20 \\
\hline
\end{tabular}




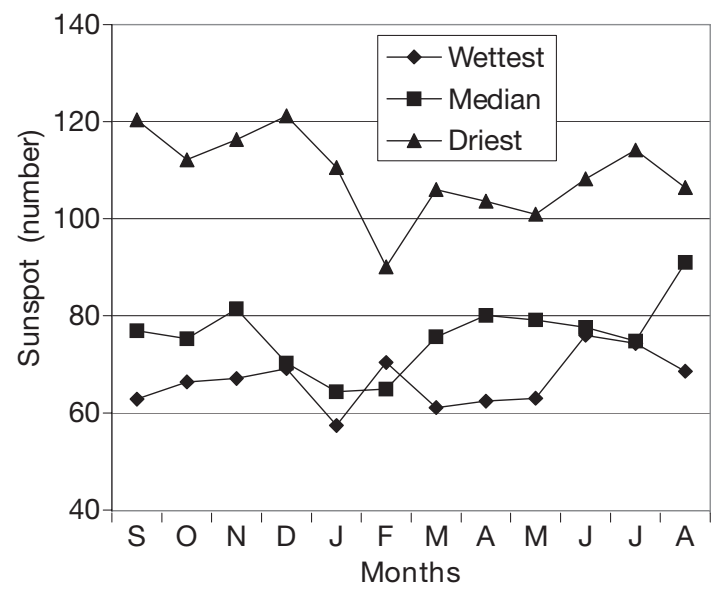

Fig. 4. Number of sunspots before, during and after the 5 driest, 5 near-median and 5 wettest May-July periods

large-scale dry or wet summer over the Canadian Prairies.

The correlation analysis reveals that the phase and strength of the QBO during the September through January period appears to influence Prairie rainfall during the May-July period (Table 2 and Fig. 5). A consistently easterly QBO between September and January is indicative of median to low rainfall during the May-July period. A westerly phase of the QBO, if present during the fall and winter months, appears to foreshadow heavy rainfall the following summer, again $6 \mathrm{mo}$ in advance of the critical June-July period.

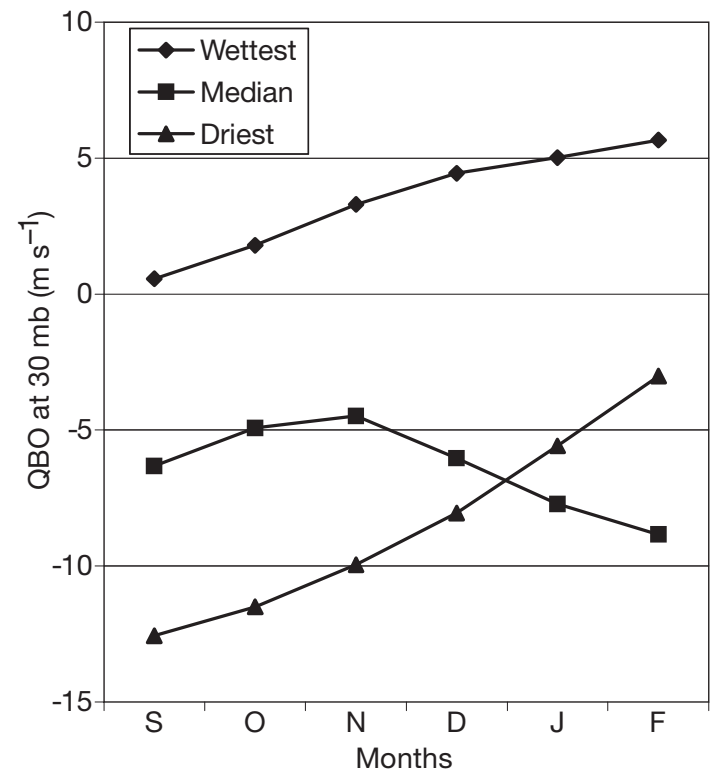

Fig. 5. Stratospheric wind composite during the fall and winter months prior to the 5 wettest, 5 median and 5 driest May-July periods
The driest, wettest and near-median June-July periods for the 1950-2004 period were:

- (driest) 1961, 1967, 1974, 1985, 2003

- (wettest) 1963, 1971, 1983, 1991, 1991

- (near-median) 1955, 1966, 1969, 1975, 2002

Patterns depicted in Fig. 6 in large part replicate the findings of Garnett et al. (1998) and Garnett (2002) whereby persistently warmer (cooler) than normal SSTAs in the Niño 3 region of the east equatorial Pacific favor (disfavor) summer precipitation over the Canadian Prairies during the summer months. In June-July periods ranked near the median JuneJuly rainfall, Niño 3 SSTAs summations are closer to zero.

The single most important month in determining spring wheat and canola yield is July (Table 1). The driest, wettest, and near-median July rainfall years for the period 1950-2004 were as follows:

- (driest) 1959, 1960, 1967, 1984, 1985

- (wettest) 1982, 1983, 1986, 1987, 1993

- (near-median) 1952, 1966, 1968, 1991, 1995

Driest (wettest) Julys occur with persistent La Niña (El Niño) conditions during the winter and spring months leading up to the critical July period when spring wheat and canola crops pass through the highly weather-sensitive heading/flowering stage (Fig. 7). In July periods with moderate rainfall Niño 3 SSTA summations are close to zero.

Table 2 reveals significant correlations between SSTAs in the Niño 3.4 region in March and April with June-July precipitation over the Canadian Prairies.

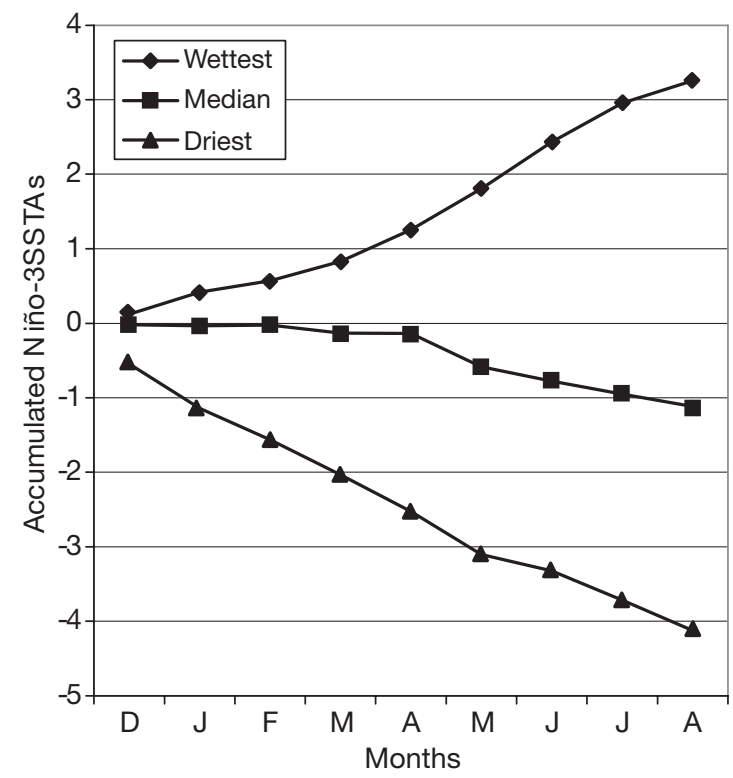

Fig. 6. Accumulated Niño 3 sea-surface temperature anomalies (SSTAs) during the wettest, driest and near-median June-July periods 


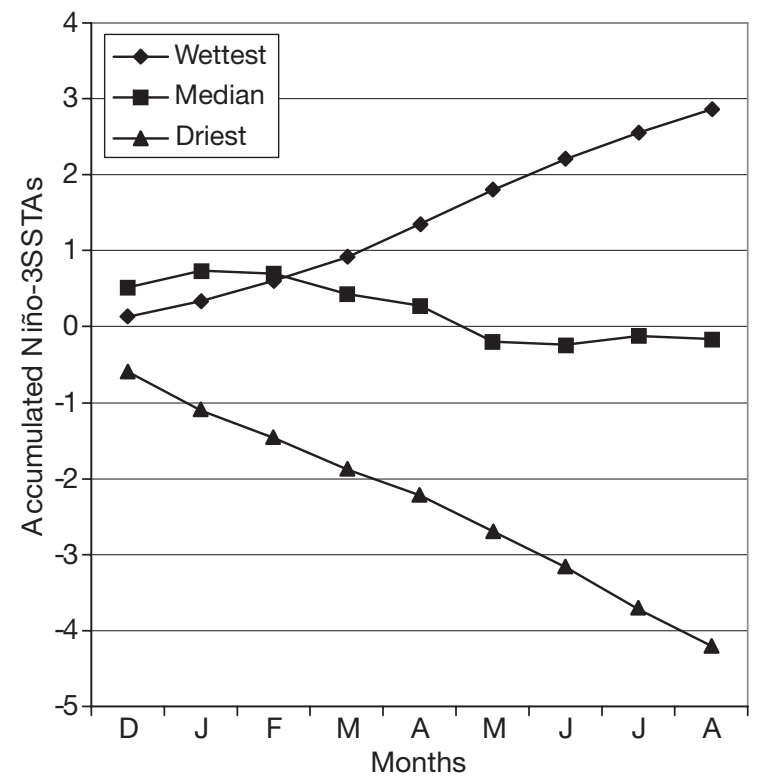

Fig. 7. Accumulated Niño 3 SSTAs during the driest, wettest and near-median July periods

The Niño 3.4 region straddles both the Niño 4 and Niño 3 regions in the east equatorial Pacific, and is the region used by the Climate Prediction Center (Washington, DC) for determining the existence of El Niño or La Niña conditions. Composite analysis was done with the Niño 3.4 region with reference to June-July precipitation over the Canadian Prairies.

Fig. 8 is similar to Figs. 6 \& 7, underlining the importance of the persistence of SSTs in the east equatorial region in the winter and spring seasons in producing June-July rainfall on the Canadian Prairies.

The coefficients of correlation presented in Table 2 indicate that more (less) extensive than normal NAS in April is prohibitive of (conducive to) May-July rainfall over the Canadian Prairies. The correlation was stronger with June-July precipitation than May-July precipitation, hence composite analysis was done with June and July precipitation. NAS is only available since 1974 . The driest June-July periods for 1974-2004 were 1974, 1979, 1984, 1985 and 2003; the wettest were 1983,1990,1991, 1993, and 2000 .

A higher (lower) than normal autumn, winter and spring NAS was unfavorable (favorable) for June-July rainfall over the Canadian Prairies (Fig. 9). This finding is similar to Garnett \& Khandekar's (1992) observation that a heavier than normal Eurasian snow cover in all seasons minimizes Indian monsoon performance. In the case of the Canadian Prairies, above-normal autumn, winter and spring NAS, leading up to the critical June-July period, mitigates rainfall during June and July. Correlation

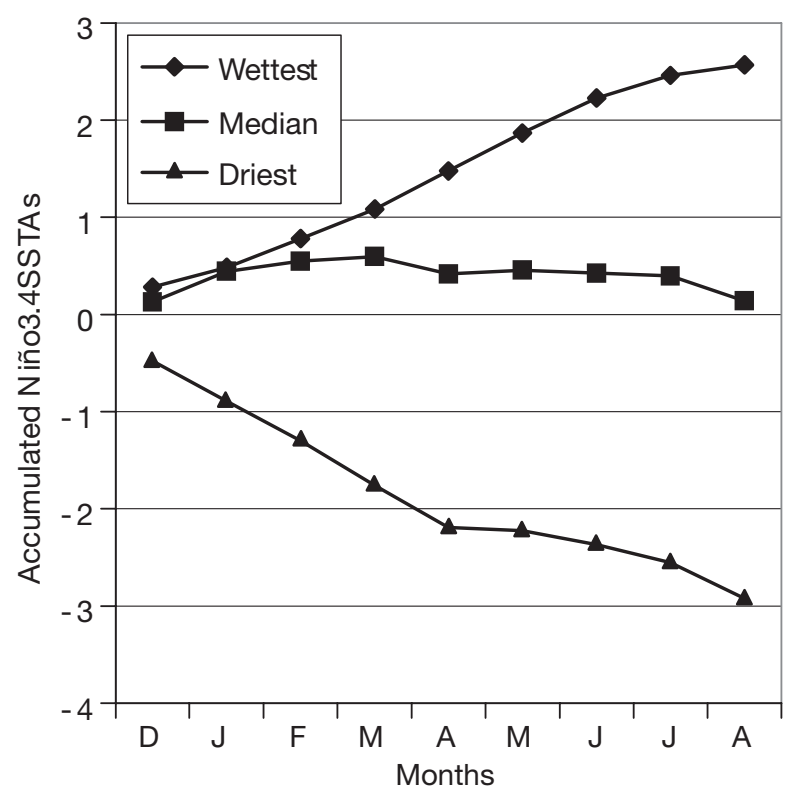

Fig. 8. Accumulated Niño 3.4 SSTAs during wettest, driest and near-median June-July periods

analysis suggests that the spatial extent of spring NAS, especially during April, may influence MayJuly rainfall. The mechanism for this finding probably relates to the fact that El Niño brings warm, dry winters to North America, while La Niña brings cold snowy winters and there is sufficient persistence to have the summers followed by cool, wet conditions in the case of El Niño and hot, dry conditions in the case of La Niña (demonstrated in Figs. 6, 7 \& 8).

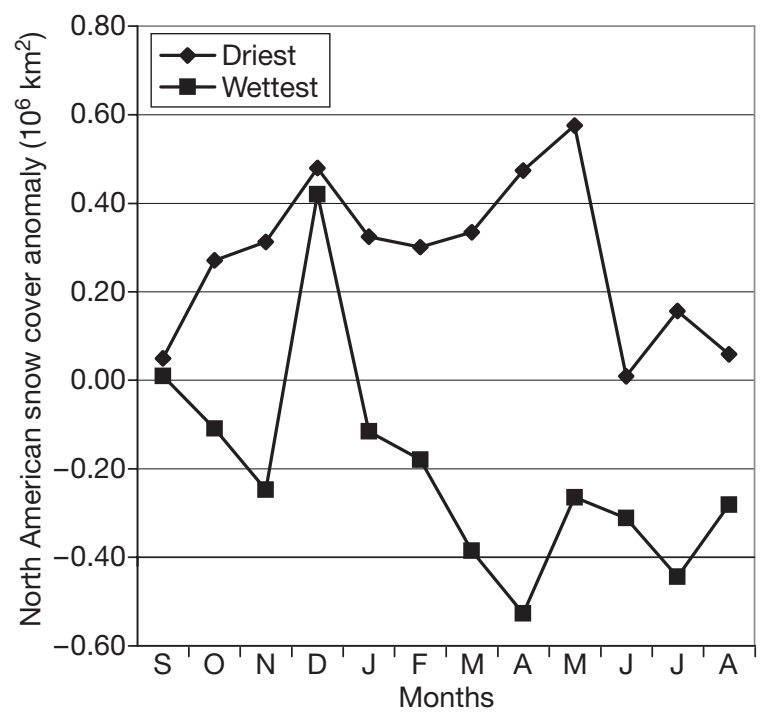

Fig. 9. North American snow cover extent anomaly before, during and after the driest and wettest June-July periods over the Canadian prairies 


\section{CONCLUSIONS}

This study has explored the correlates of sunspot activity and selected large-scale atmospheric features with Canadian regional seasonal weather, with implications for crop yield and agronomy. The selected atmospheric variables analyzed included the stratospheric QBO, ENSO, and NAS, and their effects on Canadian summer rainfall, a key variable for establishing grain yield.

Extremely dry and wet summers over the Canadian Prairies can be discerned in the multi-seasonal evolution of sunspot activity and large-scale atmospheric features such as QBO, ENSO and NAS. Figs. 2 to 6 exhibit distinctly different profiles for extremely dry, extremely wet and near-median May-July periods, thus indicating predictive value when operational research is performed with these composites.

Our findings also point towards global scale teleconnections; 1988, 1961 and 1970 were years of surplus monsoons in India (Khandekar \& Neralla 1984, Garnett \& Khandekar 1992). Garnett (2002) observed that these years had the first, second and fifth hottest June-July periods in Saskatchewan for 1950-1998, and 1961 and 1988 brought the 2 most serious Canadian Prairie droughts since 1950, with respect to impact on spring wheat yield (Garnett 2005). This indicates that there is potential gain in assessing the impact of the Indian monsoon circulation on North American agriculture by monitoring the main forcing functions that govern the performance of the Indian monsoon and anticipating how the Indian monsoon will perform each year.

Synergistically, a high sunspot number, easterly phase of the QBO, persistent La Niña conditions during the winter and spring months and anomalously extensive NAS in the spring months prior to the growing season are indicative of an extremely dry May-July period on the Canadian Prairies, with implications for crop yields. The 2001 drought was the most severe since 1988. Determining factors included a high sunspot number, easterly phase of the QBO and La Niña conditions as set forth in this study. The studies of B. W. Currie \& Venkatarangan (1978) and R. G. Currie (1984) strongly imply that high sunspot activity was a factor behind the widespread drought in North America in the 1930s.

The findings of this study can help in developing a climatic early warning system, and minimizing potential agronomic loss. The differences in the value of wheat crop between low and high yielding years reveal the social and agronomic significance of predictive tools and early warning systems. Based on the average price of spring wheat for the period 1993-1997 of \$162 (Canadian) per tonne, the difference in value of the spring wheat crop in low yielding years versus high yielding years in Saskatchewan was $\$ 900$ million (Canadian) (Garnett 2002). As Saskatchewan accounts for $38 \%$ of Canada's wheat production (1995-1999), this would translate to $\$ 2.3$ billion (Canadian) overall.

Finally, the analyses of this study were based on zero order correlation coefficients, and thus have shed light on relationships between large-scale atmospheric features and regional seasonal weather conditions, without controlling other explanatory variables. In order to further enhance our understanding of the impact of atmospheric variables on seasonal weather, multivariate statistical tools, such as linear regression models, could be used in future research.

Acknowledgements. We thank the Community University Research Alliance Social Science and Humanities Research Council (SSHRC), Ottawa, Canada, for financial assistance in procuring the climate data.

\section{LITERATURE CITED}

Currie BW, Venkatarangan P (1978) Relationship between solar disturbances and precipitation on the Canadian prairies. Institute of Space and Atmospheric Studies, University of Saskatchewan Archives, Saskatoon

Currie RG (1984) Periodic (18.6) and cyclic (11-year) induced droughts and floods in western North America. J Geophys Res 89:7215-7230

Currie RG, O'Brien DP (1990) Deterministic signals in precipitation records from the American corn belt. Int J Climatol 10:179-189

Garnett ER (2002) Long-lead forecasting of precipitation and wheat yields in Saskatchewan using teleconnection indices. MSc thesis, University of Saskatchewan, Saskatoon

Garnett ER (2005) Impact of drought on grain yields in Canada and elsewhere. In: Sauchyne D, Khandekar ML, Garnett ER (eds) The science, impacts and monitoring of drought in western Canada. Canadian Plains Research Center, University of Regina, Regina

Garnett ER, Khandekar ML (1992) The impact of large-scale atmospheric circulations and anomalies and Indian monsoon droughts and floods and on world grain yields - a statistical analysis. J Agric For Meteorol 61:13-128

Garnett ER, Babb JC, Khandekar ML (1997) Forecasting of weather and crop yield over the Canadian prairies in 1997: a verification study. In: Lefaivre L, Khandekar ML, Garnett ER (eds) Proceedings of the long-range weather and crop forecasting working group meeting III. Canadian Meteorological Center, Montreal

Garnett ER, Khandekar ML, Babb JC (1998) On the utility of ENSO and PNA indices for long-lead forecasting of summer weather over the crop-growing region of the Canadian prairies. Theor Appl Climatol 60:37-45

Gray WM, Sheaffer JD, Knaff JA (1992) Influence of the stratospheric QBO on ENSO variability. J Meteorol Soc Japan 70(5):975-994

Hsieh WW, Tang B, Garnett ER (1999) Teleconnections between Pacific sea surface temperatures and Canadian prairie wheat yield. J Agric For Meteorol 96:209-217 
Khandekar ML (1996) El Niño/southern oscillation, Indian monsoon and world grain yields - a synthesis. In: El-Sabh MI (ed) Land-based and marine hazards. Kluwer Academic Publishers, Dordrecht, p 79-95

Khandekar ML, Neralla VR (1984) On the relationship between the sea surface temperatures in the equatorial Pacific and Indian monsoon rainfall. Geophys Res Lett 11:1137-1140

Mukherjee BK, Reddy RS, Murty BHVR (1979) High-level warnings, winds and Indian summer monsoon. Mon Weather Rev 107:1581-1588

Mukherjee BK, Indira K, Reddy RS, Murty BHVR (1985) Quasi-biennial oscillation in stratospheric zonal wind and Indian summer monsoon. Mon Weather Rev 1/3: 1421-1424

Shabbar A, Khandekar ML (1996) The impact of El NiñoSouthern Oscillation on the temperature field over Canada. Atmosphere-Ocean 34(2):401-416

Shabbar A, Bonsal B, Khandekar ML (1997) Canadian precip-

Editorial responsibility: Madhav L. Khandekar,

Ontario, Canada itation patterns associated with the Southern Oscillation. J Clim 10:3016-3027

Thompson LM (1973) Cyclical weather patterns in the middle latitudes. J Soil Water Conserv 28:87-89

Udelhofen PM, Cess RD ( 2001) Cloud cover variations over the United States: an influence of cosmic rays or solar variability? Geophys Res Lett 28(13):2617-2620

Walker GT, Bliss EW (1932) World weather. V. Memo, R Meteorol Soc 4(36):53-84

Wheaton EE (1991) Climatic variability and agricultural ecosystems-some inter-relationships. In: Dizkowski P (ed) Changing climate in relation to sustainable agriculture. Pub. No. E2900-4D-91, Saskatchewan Research Council (SRC), Saskatoon, p 43-45

van Loon H, Labitzke K (1988) Association between the 11year solar cycle, the QBO, and the atmosphere. Part II. Surface and $700 \mathrm{mb}$ in the northern hemisphere in winter. J Clim 1:905-920

Submitted: November 22, 2005; Accepted: February 21, 2006 Proofs received from author(s): April 26, 2006 